\title{
Dynamics of $S$. cerevisiae proteomic and transcriptomic response to changes in aeration conditions
}

\author{
A. Rozanov*, I. Meshcheryakova, S. Bannikova, D. Oshchepkov, G. Vasiliev, S. Peltek \\ Institute of Cytology and Genetics SB RAS, Novosibirsk, Russia \\ *e-mail: sibiryak.n@gmail.com
}

Key words: metabolic analysis, S.cerevisiae, RNAseq, proteomics

Motivation and Aim: The microorganisms widely used in biotechnologies to produce various substances, from simple primary metabolites such as alcohol to complex organic molecules and proteins with a specific set of modifications. Yeasts are the most widely used producers of various substances. Traditionally, yeast has been used for cultivation in anaerobic environments to produce alcohol. Currently, they are widely used in aerobic processes. Modern technological processes are carried out in large volumes and with high-density cultivation. Microorganisms are strained in such conditions because of the difficulties in mass transfer. The fluctuation of the oxygen concentration is the most significant. In the work, we study the dynamics of the transcriptom and proteome response S. cerevisiae to stop to stop aeration.

Methods and Algorithms: Scheme of the experiment: yeast was cultivated in a 51 Biostat b-dcu II Sartorius fermenter. Strain FY1679 was used. Medium: YNB + $2 \%$ glucose, + required amino acids, 2.51. Conditions: temperature $30^{\circ} \mathrm{C}$, mixing speed $800 \mathrm{rpm}$, air 2 liters per minute. The culture was grown until an optical density of $\mathrm{OD}_{600}=0.8$. In that time takin samples. The air supply was off and the nitrogen supply was on. Samples for analysis were taken at 5, 10, 20, 40 and 80 minutes. Further RNAseq and differentiated proteomic analysis of the samples were performed.

Results: According to proteome analysis, half of all visualized proteins were observed in concentration changes. a concentration of $3 \%$ (15 of 500) proteins decreasing after the $10^{\text {th }}$ or $5^{\text {th }}$ minute after oxygen off, and $30 \%$ (151 of 500) of proteins - increased ( $\mathrm{p}<$ $0.05)$. The main changes in the protein content occur between the $10^{\text {th }}$ and $20^{\text {th }}$ minutes, which is undoubtedly a reflection of the metabolic rearrangements occurring at this time in culture. At the moment, 162 proteins have been identified. Также в настоящий момент идет обработка данных RNAseq. The results of bioinformatic processing and analysis results will be presented in the report.

Acknowledgements: Thereported study was fundedby ICGSBRASNo.0324-2018-0017. 